\title{
Mechanical Modeling of The Leg Assembly Acting on the The Ankle: a CFD Analysis Study for Stress and Strain Measurement
}

\author{
Mohamed Bjaoui $^{1}$, Houneida Sakly*2, Mourad Said ${ }^{3}$, Naoufel Kraiem² and Med Salim Bouhlel ${ }^{1}$ \\ ${ }^{1}$ The Information and Telecommunications Science and Technology Research Unit (SETIT) Laboratory SFAX-The National Insti- \\ tute of Engineering of Sfax (ENIS), Tunisia
}

${ }^{2}$ RIADI Laboratory -National Institute of Computer Sciences, University of Mannouba, Tunisia

${ }^{3}$ Radiology and Medical Imaging Unit, International Center Carthage Medical, Tunisia

*Corresponding author: Houneida Sakly, RIADI Laboratory -National Institute of Computer Sciences, University of Mannouba, Tunisia

\section{ARTICLE INFO}

Received: 㗀 April 29, 2020

Published: May 05, 2020

Citation: Mohamed B, Houneida S, Mourad S, Naoufel K, Med Salim B. Mechanical Modeling of The Leg Assembly Acting on the The Ankle: a CFD Analysis Study for Stress and Strain Measurement. Biomed J Sci \& Tech Res 27(3)-2020. BJSTR. MS.ID.004503.

Keywords: 3D Leg Assembly; Ankle; Boundary Conditions; CFD; Stress; Strain

\section{ABSTRACT}

The increasing incidence of fractures or bone accidents for aged or injured patients is seen as a challenge for experts. Following our study of an accidental case wearing a prosthetic leg, the risk of poor adaptation to the ankle following the change in biomechanics was described. This study aims to analyze the evolution of the proximal biomechanics of this leg assembly using dynamic calculation fluid analysis (CFD) and to extract parameters such as deformation and stress measurements which could predict the probability of well adaptation inside the ankle and simulate the measurement of strain and stress. A 3D leg assembly model is constructed by configuring the material and the boundary conditions and respecting the specific characteristics of the patient, providing a realistic and efficient structural analysis. This study describes a 3D construction process for the ankle in leg assembly as well as the generation of the mesh on the basis of a parallel processing of 16 processors turned in the cloud.

\section{Mini Review}

Imaging techniques are considered useful approaches for nondestructively describing synthetic or natural biomaterials [1]. The mechanisms of orthopedic prostheses and the local CFD flow phenomena are still ambiguous for the experts. In particular, the distribution of flow in the prosthesis system of patients with bone diseases is a challenge to understand. For decades, the intrinsic movement of the foot and ankle complex during walking activity has been hindered by simplified foot modeling as a single functional segment [2]. The issue has partially remedied for the development of three-dimensional (3D) multi-assembly foot models [3]. Therefore, these 3D models of established lower limbs have proven their clinical impact by detecting impairments in foot mobility. In a more specific way, the biomechanics of the foot and ankle was analyzed via the kinematics of the walking cycle treated in different fields such as invasive bone pins, biplanar video radiography [4], studies of non-invasive surface markers [5,6]. As well as study of foot kinematics using a dynamic walking cadaver model, and plantar strain measurements [7-11]. Improvements in imaging techniques combined with advanced simulation methods, such as CFD, can provide better understanding as well as meaningful analysis measures for our leg assembly case and in a more specific method to perform the strain and stress at the ankle joint.

\section{Material and Methods}

A 3D model was produced for the leg assembly with $0,5 \mathrm{~m}$ of length and steel material composed of 738 faces 13 volumes, 1259 nodes, 1955 edges. A Tet-Dominant algorithm was run for fast generation and automated tetrahedral meshes as described in [12]. The linear elastic behavior has been described with the initial conditions for the Young's modulus, the Poisson's ratio and the density parameters. the ankle joint with $0,1 \mathrm{~m}$ of length is made of aluminum material with a modeling of 4 volumes composed of 130 faces, 4 volumes, 219 nodes, 335 edges as shown in Table 1.

\section{Result}

The ankle prosthesis was tested under three axes of translation in the nodal directions $\mathrm{x}, \mathrm{y}$ and $\mathrm{z}$ and rotations around the nodal 


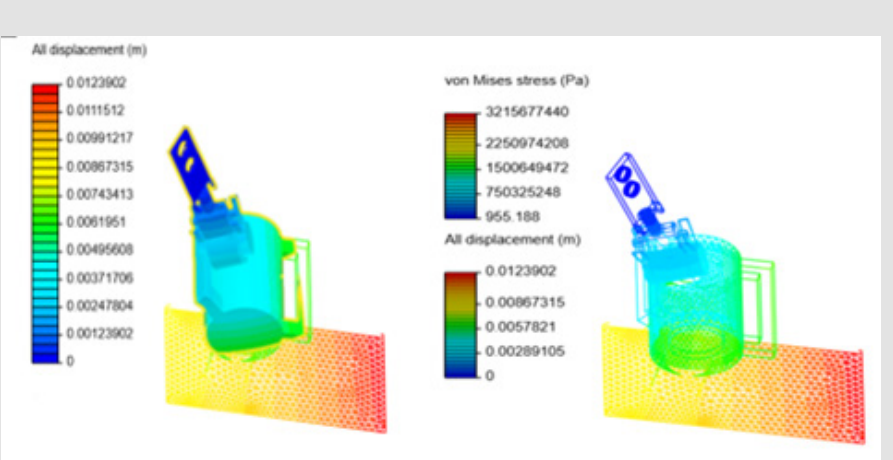

(a)

(b)

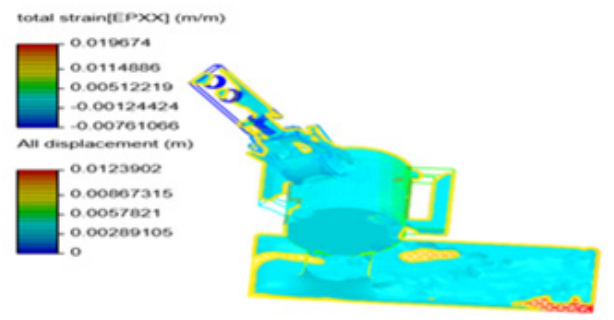

(c)

Figure 2

\section{Conclusion}

This study reports an attempt to perceive the kinetic behavior of several joints of the foot through the estimation of stress and strain during the act of walking. The ankle joints of the foot adopt a stabilized resistive configuration during most of the support phase. The concept of stabilization, resistance and propulsion should be studied in subjects with foot and ankle disorders

\section{Acknowledgment}

International Medical Carthage Center supported this work. Special thanks to the medical staff for providing us with as access to the archive of patients and the administrative framework for the warm welcome in their team.

\section{Conflicts of Interest}

No conflict to declare.

\section{References}

1. Mootanah R (2006) Creation of accurate 3D models of reconstructed bones and joints for evaluations of surgical fixation techniques by finite element analysis. Journal of Biomechanics 39: S424..

2. Deschamps K, Filip Staes, Philip Roosen, Frank Nobels, Kaat Desloovere, et al. (2011) Body of evidence supporting the clinical use of 3D multisegment foot models: a systematic review. Gait Posture 33(3): 338-349.

3. Bruening DA, Takahashi KZ (2018) Partitioning ground reaction forces for multi-segment foot joint kinetics. Gait Posture 62: 111-116.

4. Kessler SE, Michael J Rainbow, Glen A Lichtwark, Andrew G Cresswell, Susan E D’Andrea, et al. (2019) A Direct Comparison of Biplanar Videoradiography and Optical Motion Capture for Foot and Ankle Kinematics Front. Bioeng. Biotechnol 7.
5. Westblad P, Hashimoto T, Winson I, Lundberg A, A Arndt (2002) Differences in ankle-joint complex motion during the stance phase of walking as measured by superficial and bone-anchored markers. Foot Ankle Int 23(9): 856-863

6. Zorina OA, Boriskina OA, Magomedov RN, Prohodnaya VA, Mironycheva $\mathrm{KV}$, et al. (2019) [Dynamics of bone metabolism markers in oral fluid after surgical treatment of chronic periodontal disease with various osteoplastic materials]. Stomatologiia (Mosk) 98(2): 27-30

7. Nester C, Jones RK, Liu A, Howard D, Lundberg A, et al. (2007) Foot kinematics during walking measured using bone and surface mounted markers. J Biomech 40(15): 3412-3423.

8. Nester CJ (2009) Lessons from dynamic cadaver and invasive bone pin studies: do we know how the foot really moves during gait?. J Foot Ankle Res 2: 18

9. Leardini A, Benedetti MG, Berti L, Bettinelli D, Nativo R, et al. (2007) Rear-foot, mid-foot and fore-foot motion during the stance phase of gait Gait Posture 25(3): 453-462.

10. Nester CJ, Liu M, Ward E, Howard D, Cocheba J, et al. (2007) In vitro study of foot kinematics using a dynamic walking cadaver model. Journal of Biomechanics 40( 9): 1927-1937.

11. Lundgren P, Nester C, Liu A, Arndt A, Jones R, et al. (2008) Invasive in vivo measurement of rear-, mid- and forefoot motion during walking. Gait Posture 28(1): 93-100.

12. Sakly H, Said M, Tagina M (2019) Femur Bone Stress Analysis in CFD Modules with Parallel Processing. IJEAT 9(2): 903-906.

13. Bruening DA, Cooney KM, Buczek (2012) Analysis of a kinetic multi-segment foot model. Part I: Model repeatability and kinematic validity. Gait Posture 35(4): 529-534.

14. Jacob (2001) Forces acting in the forefoot during normal gait - an estimate. Clinical Biomechanics 16 (9): 783-792.

15. Kelly LA, Cresswell AG, Racinais S, Whiteley R, Lichtwark G (2014) Intrinsic foot muscles have the capacity to control deformation of the longitudinal arch. Journal of The Royal Society Interface 11(93): 20131188. 
ISSN: 2574-1241

DOI: $10.26717 /$ BJSTR.2020.27.004503

Houneida Sakly. Biomed J Sci \& Tech Res

(c) (i) This work is licensed under Creative BY Commons Attribution 4.0 License

Submission Link: https://biomedres.us/submit-manuscript.php

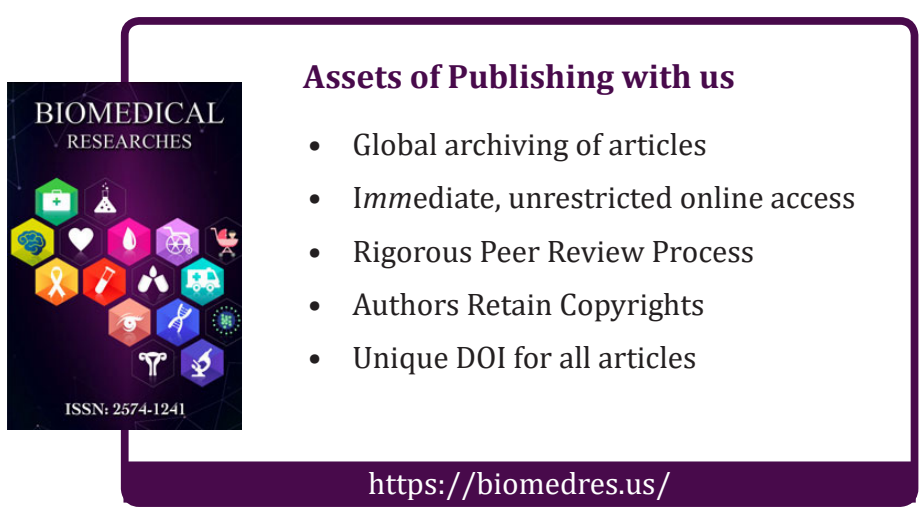

